CLINICAL STUDY

\title{
High serum adiponectin is associated with favorable lipoprotein subclass profile in 6.4-year follow-up
}

\author{
Mauno Vanhala ${ }^{1,6}$, Linda S Kumpula ${ }^{2}$, Pasi Soininen ${ }^{2,3}$, Antti J Kangas ${ }^{2}$, Mika Ala-Korpela ${ }^{2,3,4}$, \\ Hannu Kautiainen ${ }^{1,5}$, Pekka Mäntyselkä ${ }^{6}$ and Juha Saltevo ${ }^{7}$ \\ ${ }^{1}$ Unit of General Practice, Central Finland Central Hospital, Keskussairaalantie 19, 40620 Jyväskylä, Finland, ${ }^{2}$ Computational Medicine Research Group, \\ Faculty of Medicine, Institute of Clinical Medicine, University of Oulu and Biocenter Oulu, 90014 Oulu, Finland, ${ }^{3}$ NMR Metabonomics Laboratory, \\ Department of Biosciences, University of Eastern Finland, 70211 Kuopio, Finland, ${ }^{4}$ Department of Internal Medicine, Institute of Clinical Medicine, \\ Biocenter Oulu and Clinical Research Center, University of Oulu, 90014 Oulu, Finland, ${ }^{5}$ ORTON, Rehabilitation Unit, O0280 Helsinki, Finland, ${ }^{6}$ Unit of \\ Primary Health Care, University of Eastern Finland and Kuopio University Hospital, 70211 Kuopio, Finland and ${ }^{7}$ Department of Medicine, Central \\ Finland Central Hospital, 40620 Jyväskylä, Finland
}

(Correspondence should be addressed to M Vanhala at Unit of General Practice, Central Finland Central Hospital; Email: mauno.vanhala@ksshp.fi)

\begin{abstract}
Objective: Adiponectin is linked to a favorable lipoprotein profile, but potential longitudinal associations are not known.

Design: A population-based follow-up study of all inhabitants born in 1942, 1947, 1952, and 1957 $(n=1294)$ in Pieksämäki, a town in Finland. Of the 690 subjects participating in both the check-ups, 228 subjects with diabetes or any medication for dyslipidemia, high blood pressure, or diabetes were excluded. The final study population consisted of 462 (182 men and 280 women) apparently healthy subjects.

Methods: Main outcome measures were lipoprotein particle sizes and concentrations, apolipoprotein A-1 (APOA1) and APOB levels at baseline and follow-up across baseline adiponectin tertiles. Serum adiponectin concentrations were determined using an enzyme immunoassay, and lipoprotein subclasses using proton nuclear magnetic resonance spectroscopy.

Results: At the second health check-up 6.4 years later, the very low-density lipoprotein particle concentration decreased across the baseline adiponectin tertiles in men from 1.04 (0.28) to 0.91 $(0.29) \mathrm{nmol} / \mathrm{l}(P$ for linearity $=0.011)$ and in women from $0.92(0.32)$ to $0.80(0.24) \mathrm{nmol} / \mathrm{l}$ $(P=0.002)$. Correspondingly, the mean high-density lipoprotein particle size increased from 9.78 to $9.90 \mathrm{~nm}$ in men $(P<0.006)$ and from 10.00 to $10.14 \mathrm{~nm}$ in women $(P<0.001)$.

Conclusion: The favorable links between adiponectin and lipoproteins are detectable 6.4 years later.
\end{abstract}

European Journal of Endocrinology $164549-552$

\section{Introduction}

Adiponectin, an adipokine secreted by adipocytes, is related to insulin sensitivity and lipoprotein metabolism (1). In cross-sectional studies, adiponectin independently associates with very low-density lipoprotein (VLDL), low-density lipoprotein (LDL), and high-density lipoprotein (HDL) particle concentrations and sizes (2). Adiponectin also associates with apolipoprotein A-1 (APOA1) and APOB levels by regulating VLDL APOB-100 catabolism (3). No studies about the association of adiponectin with APOA1, APOB, or lipoprotein particle concentrations and size in a longitudinal setting are available.

\section{Research design and methods}

The study population consisted of middle-aged, Caucasian subjects $(n=1294)$ born in $1942,1947,1952$,
1957, and 1962 (the entire age group) in Pieksämäki, a town in the eastern Finland. The study protocol was approved by the ethics committee of the Kuopio University Hospital and the University of Kuopio. A total of 923 out of 1294 subjects $(71.3 \%)$ participated in an initial examination in 1997-98, and 690 of these participated in a second health check-up in 2003-2004 (4). We excluded 11 subjects with known diabetes and 217 subjects having any medication known to affect insulin sensitivity or lipid metabolism (i.e. lipid-lowering, antihypertensive, or diabetes medication). The apparently healthy study population included 182 men and 280 women.

The same two trained nurses performed the study process at both the health check-ups. After obtaining written informed consent, participants underwent an interview followed by physical examination. At both the check-ups, all the subjects completed a questionnaire including questions about their medication and disease history. Height and weight were measured to the 
nearest $0.5 \mathrm{~cm}$ and $0.1 \mathrm{~kg}$ respectively. Body mass index (BMI) was calculated as weight $(\mathrm{kg})$ divided by height $(\mathrm{m})$ squared.

Fresh serum samples were drawn after an overnight fast. Plasma was separated by centrifugation for the determination of glucose, lipids, and fasting insulin, and the samples were frozen immediately and stored in $-75^{\circ} \mathrm{C}$. Plasma insulin was determined using the Phadeseph Insulin RIA 100 method (Pharmacia Diagnostics AB). Plasma glucose concentration was measured by automated colorimetric method (Peridochrom Glucose GOD-PAP, Boehringer, Germany), and the quantitative insulin sensitivity check index (QUICKI) was calculated as follows: QUICKI $=1 /(\log \mathrm{FPI}+\log$ FBG), where FPI is the fasting plasma insulin level expressed as $\mathrm{mU} / \mathrm{l}$, and $\mathrm{FBG}$ is the fasting plasma glucose level expressed as $\mathrm{mg} / \mathrm{dl}$ (5). Serum adiponectin was determined in 2002 with an enzyme immunoassay (Human Adiponectin ELISA Kit, B-Bridge International, Inc., Mountains View, CA, USA) (6). Proton NMR spectroscopy was used to quantify lipoprotein subclasses and particle concentrations in native serum samples in 2009 (7). The lipoprotein subclasses are calibrated according to HPLC and defined according to the following criteria: i) as one of six VLDL subclasses extremely large (with particle diameter from $\sim 75 \mathrm{~nm}$ upward and possibly containing chylomicron particles), very large (average particle diameter of $64.0 \mathrm{~nm}$ ), large (53.6 nm), medium $(44.5 \mathrm{~nm})$, small $(36.8 \mathrm{~nm})$, and very small $(31.3 \mathrm{~nm})$; ii) as intermediate-density lipoprotein (IDL) $(28.6 \mathrm{~nm})$; iii) as one of three LDL subclasses, including large $(25.5 \mathrm{~nm})$, medium (23.0 nm), and small (18.7 nm); and iv) as one of four HDL subclasses - very large $(14.3 \mathrm{~nm})$, large $(12.1 \mathrm{~nm})$, medium $(10.9 \mathrm{~nm})$, and small $(8.7 \mathrm{~nm})$. The mean size for VLDL, LDL, and HDL particles was calculated by weighting the corresponding subclass diameters with their particle concentrations. IDL particles were included in the LDL measure. The results are expressed as the mean \pm S.D.

In the statistical analyses, subjects were divided into sex-specific groups according to adiponectin tertiles. Generalized linear models were used to compare baseline and follow-up data between groups. Age, BMI, QUICKI, and baseline values were introduced into the models as covariates. Correlation coefficients were calculated by the Spearman method, using Sidakadjusted probabilities.

\section{Results}

The apparently healthy study population included 182 men and 280 women (mean age at baseline $44.5 \pm 6.0$ and $44.9 \pm 6.0$ years respectively). The mean time between the two health check-ups was 6.4 years for both genders.
Table 1 shows the age, BMI, and QUICKI across the gender-specific baseline adiponectin tertiles. In the first check-up, 41 women (14.4\%) had hormonal contraception and 15 (5\%) had estrogen replacement therapy. At the second health check-up, none of the women had contraceptive hormones, but $78(27.5 \%)$ of them had estrogen replacement therapy. Hormonal contraception or replacement therapy did not vary across adiponectin tertiles.

At baseline, across adiponectin tertiles, the mean HDL particle size and particle concentration as well as APOA1 concentration increased, and VLDL particle concentration and APOB level decreased in both genders statistically significantly (data not shown). LDL particle size or particle concentration did not associate with adiponectin tertiles.

Baseline adiponectin concentration correlated positively with the mean HDL particle size in men $(r=0.25, P<0.05)$ and in women $(r=0.25, P<0.001)$ measured in the second health check-up 6.4 years later. In women, baseline adiponectin correlated inversely with VLDL particle size $(r=-0.22, P<0.01)$. There was no correlation between adiponectin and the future LDL particle size or concentration.

The mean HDL particle size measured in the second health check-up increased across the baseline adiponectin tertiles from 9.78 to $9.90 \mathrm{~nm}$ in men $(P<0.006)$ and from 10.00 to $10.14 \mathrm{~nm}$ in women $(P<0.001)$. Negative associations were found for the baseline adiponectin tertiles and VLDL particle concentration in both genders $(P=0.011$ for men and $<0.001$ for women), and VLDL particle size $(P<0.001)$ and APOB $(P=0.040)$ in women. These associations were present

Table 1 Basic characteristics of the 462 apparently healthy middleaged men and women across gender-specific adiponectin tertiles.

\begin{tabular}{|c|c|c|c|c|}
\hline & \multicolumn{3}{|c|}{ Adiponectin tertiles } & \multirow{2}{*}{$\begin{array}{c}P \text { for } \\
\text { linearity }\end{array}$} \\
\hline & I & II & III & \\
\hline \multicolumn{5}{|l|}{ Male } \\
\hline $\begin{array}{l}\text { Adiponectin } \\
\text { range }\end{array}$ & $<3.5 \mu \mathrm{g} / \mathrm{l}$ & $3.5-5.5 \mu \mathrm{g} / \mathrm{l}$ & $>5.5 \mu \mathrm{g} / \mathrm{l}$ & \\
\hline Number & 60 & 61 & 61 & \\
\hline $\begin{array}{l}\text { Age, years, } \\
\text { mean (s.D.) }\end{array}$ & $43(6)$ & $45(6)$ & $46(6)$ & 0.002 \\
\hline $\begin{array}{c}\text { BMI, } \mathrm{kg} / \mathrm{m}^{2}, \\
\text { mean (s.D.) }\end{array}$ & $27.1(3.3)$ & $25.7(2.5)$ & $25.2(3.1)$ & $<0.001$ \\
\hline $\begin{array}{l}\text { QUICKI, } \\
\text { mean (S.D.) }\end{array}$ & $0.33(0.02)$ & $0.34(0.02)$ & $0.35(0.02)$ & $<0.001$ \\
\hline \multicolumn{5}{|l|}{ Female } \\
\hline $\begin{array}{l}\text { Adiponectin } \\
\text { range }\end{array}$ & $<5.7 \mu \mathrm{g} / \mathrm{l}$ & $5.7-8.4 \mu \mathrm{g} / \mathrm{l}$ & $>8.4 \mu \mathrm{g} / \mathrm{l}$ & \\
\hline Number & 92 & 93 & 95 & \\
\hline $\begin{array}{l}\text { Age, years, } \\
\text { mean (s.D.) }\end{array}$ & $43(6)$ & $45(7)$ & $46(6)$ & 0.002 \\
\hline $\begin{array}{c}\text { BMI, } \mathrm{kg} / \mathrm{m}^{2} \\
\text { mean (S.D.) }\end{array}$ & $25.6(3.9)$ & $25.6(4.4)$ & $24.6(6)$ & 0.171 \\
\hline $\begin{array}{l}\text { QUICKI, } \\
\text { mean (S.D.) }\end{array}$ & $0.34(0.02)$ & $0.34(0.02)$ & $0.35(0.02)$ & $<0.001$ \\
\hline
\end{tabular}


Table 2 Lipoprotein particle sizes and concentrations with APOA1 and APOB concentrations across the gender-specific, 6.4 years earlier measured adiponectin tertiles.

\begin{tabular}{|c|c|c|c|c|c|c|}
\hline & \multicolumn{3}{|c|}{ Adiponectin tertiles } & \multicolumn{3}{|c|}{$P$ for linearity } \\
\hline & I Mean (S.D.) & II Mean (s.D.) & III Mean (S.D.) & Model 1 & Model 2 & Model 3 \\
\hline \multicolumn{7}{|l|}{ Male } \\
\hline VLDL size $(\mathrm{nm})$ & $37.0(1.7)$ & $36.8(1.6)$ & $36.5(1.3)$ & 0.078 & 0.97 & 0.94 \\
\hline VLDL particle concentration ( $\mathrm{nmol} / \mathrm{l})$ & $104(28)$ & $99(35)$ & $91(29)$ & 0.011 & 0.36 & 0.76 \\
\hline LDL particle size $(\mathrm{nm})$ & $23.5(0.3)$ & $23.5(0.2)$ & $23.5(0.2)$ & 0.52 & 0.99 & 0.53 \\
\hline LDL particle concentration $(\mathrm{nmol} / \mathrm{l})$ & $575(130)$ & 579 (113) & $553(136)$ & 0.38 & 0.24 & 0.25 \\
\hline HDL particle size $(\mathrm{nm})$ & $9.78(0.23)$ & $9.87(0.28)$ & $9.90(0.27)$ & 0.006 & 0.23 & 0.91 \\
\hline HDL particle concentration $(\mu \mathrm{mol} / \mathrm{l})$ & $6.76(0.89)$ & $6.89(0.83)$ & $6.71(0.92)$ & 0.75 & 0.43 & 0.009 \\
\hline APOB $(g / l)$ & $1.08(0.19)$ & $1.07(0.21)$ & $1.01(0.22)$ & 0.071 & 0.25 & 0.42 \\
\hline \multirow{2}{*}{\multicolumn{7}{|c|}{ Female }} \\
\hline & & & & & & \\
\hline VLDL particle size $(\mathrm{nm})$ & $36.4(1.4)$ & $36.2(1.4)$ & $35.8(1.0)$ & $<0.001$ & 0.13 & 0.18 \\
\hline VLDL particle concentration ( $\mathrm{nmol} / \mathrm{l})$ & $92(32)$ & $88(30)$ & $80(24)$ & 0.002 & 0.020 & 0.19 \\
\hline LDL particle size $(\mathrm{nm})$ & $23.6(0.2)$ & $23.6(0.2)$ & $23.6(0.2)$ & 0.28 & 0.79 & 0.45 \\
\hline LDL particle concentration (nmol/l) & $571(132)$ & $561(121)$ & $554(115)$ & 0.38 & 0.17 & 0.13 \\
\hline HDL particle size $(\mathrm{nm})$ & $10.00(0.24)$ & $10.05(0.25)$ & $10.14(0.25)$ & $<0.001$ & 0.004 & 0.89 \\
\hline HDL particle concentration $(\mu \mathrm{mol} / \mathrm{l})$ & $7.30(0.96)$ & $7.49(0.96)$ & $7.43(0.88)$ & 0.35 & 0.20 & 0.38 \\
\hline APOB $(g / l)$ & $1.02(0.22)$ & $0.99(0.21)$ & $0.96(0.18)$ & 0.040 & 0.031 & 0.32 \\
\hline APOA1 $(\mathrm{g} / \mathrm{l})$ & $1.69(0.21)$ & $1.74(0.22)$ & $1.77(0.20)$ & 0.015 & 0.92 & 0.26 \\
\hline
\end{tabular}

Model 1, crude; Model 2, adjusted for age, BMI, and QUICKI; Model 3, adjusted for age, BMI, QUICKI, and baseline value of the variable in question.

even after adjustment for age, BMI, and QUICKI in women. After further adjustment for the baseline value of the variable in question, there was a positive association between baseline adiponectin and HDL particle concentration $(P=0.009)$ and APOA1 $(P=0.002)$ in men (Table 2$)$.

\section{Conclusion}

The novel finding in our apparently healthy study population is that the association between high baseline adiponectin level and favorable lipid profile was observed 6.4 years later. The inverse linear association across baseline adiponectin tertiles with follow-up VLDL particle concentration, as well as a positive association with HDL particle size in both genders, suggests a healthy future lipid profile in the highest baseline adiponectin tertile. In women, there was also a statistically significant inverse association between baseline adiponectin and VLDL particle size and APOB 6.4 years later.

Obesity is associated with a low adiponectin level and an increase in hepatic secretion and delayed catabolism of VLDL APOB. These kinds of changes have lead to the accumulation of intraperitoneal fat, resulting in increased synthesis of APOB (3). Adiponectin has also been reported to reduce hepatic APOB release without influencing APOA secretion $(8,9)$. Our results showing that in women a statistically significantly (and in men almost statistically significant) lower APOB is present in the highest baseline adiponectin tertile in the second health check-up, as well as the longitudinal association of adiponectin with APOA1 level, is in line with the previous studies.
Adiponectin reduces plasma triglycerides by increasing VLDL triglyceride catabolism via increased lipoprotein lipase (LPL) activity $(10,11)$. High LPL activity has been shown to result in the production of large HDL particles that are antiatherogenic and anti-inflammatory, and protect from atherosclerosis. Adiponectin has been suggested to lead to other antiatherogenic changes in lipoprotein profiles by decreasing the synthesis of VLDL, resulting in smaller VLDL and larger HDL particles (12-14). High plasma adiponectin has shown to predict insulin sensitivity of lipid metabolism resulting in a positive association with HDL cholesterol concentration and an inverse association with triglyceride concentration $(15,16)$. This is in line with our longitudinal results showing that adiponectin was inversely correlated with VLDL particle concentration and linearly with HDL particle size in both genders, and that this association weakened after adjusting for age, BMI, and QUICKI.

Contradictory to some other studies $(1,2,12)$, we could not find any association between LDL particle size or concentration and adiponectin, not as a continuous variable nor in the tertiles. On the other hand, Shin \& Kim (17) have shown that after taking triglyceride level into account, adiponectin does not associate with LDL size, and that the most significant associations are between adiponectin and VLDL and HDL lipoproteins. The possibly explanation is in our apparently healthy study population not having dyslipidemia, hypertension, or diabetes, which all are known to associate with the presence of the small, dense LDL particles.

Recent findings have indicated that adiponectin levels are quite stable over a time period of years. Mascarinec et al. (18) have recently published a soy intervention study showing that adiponectin levels changed neither 
in 90 women of intervention group nor in 93 women of control group, regardless of a slight BMI increase during the 2-year follow-up. Our finding of the longitudinal association of adiponectin with lipoprotein particle sizes and concentrations as well as with APOA1 and APOB 6.4 years later might be due to the stability of individual adiponectin concentration over the follow-up period.

The strengths of this study are longitudinal population-based design and NMR analyses performed contemporarily for both the baseline and the follow-up serum samples. Adiponectin levels were not measured at the second health check-up, which may be considered a limitation as the relative small number of study subjects.

We conclude that high adiponectin levels mirror favorable lipid profile 6.4 years later in a populationbased apparently healthy cohort.

\section{Declaration of interest}

The authors declare that there is no conflict of interest that could be perceived as prejudicing the impartiality of the research reported.

\section{Funding}

This research did not receive any specific grant from any funding agency in the public, commercial or not-for-profit sector.

\section{Acknowledgements}

We acknowledge funding from the Academy of Finland's Responding to Public Health Challenges Research Programme (SALVE) (MAK).

\section{References}

1 Kantartzis K, Rittig K, Balletshofer B, Machann J, Schick F, Poburska K, Fritsche A, Häring H-U \& Stefan N. The relationship of plasma adiponectin with a favorable lipid profile, decreased inflammation and less ectopic fat accumulation depend on adiposity. Clinical Chemistry 200652 1934-1942. (doi:10. 1373/clinchem.2006.067397)

2 Weiss R, Otvos JD, Flybjerg A, Miserez AR, Frystyk J, Sinnreich R \& Kark JD. Adiponectin and lipoprotein particle size. Diabetes Care 200932 1317-1319. (doi:10.2337/dc09-0084)

3 Ng TW, Watts GF, Farvid MS, Chan DC \& Barrett PH. Adipocytokines LDL metabolism. Independent regulatory effects of adiponectin, insulin resistance, and fat compartments on VLDL apolipoprotein B-100 kinetics. Diabetes $2005 \mathbf{5 4}$ 795-802. (doi:10.2337/diabetes.54.3.795)

4 Ahonen T, Kautiainen H, Keinänen-Kiukaanniemi S, Kumpusalo E \& Vanhala M. Gender difference among smoking, adiponectin, and high-sensitivity C-reactive protein. American Journal of Preventive Medicine 200835 598-601. (doi:10.1016/j.amepre.2008.09. 011)

5 Katz A, Nambi SS, Mather K, Baron AD, Follmann DA, Sullivan G \& Quon MJ. Quantitative insulin sensitivity check index: a simple, accurate method for assessing insulin sensitivity in humans. Journal of Clinical Endocrinology and Metabolism $2000 \mathbf{8 5}$ 2402-2410. (doi:10.1210/jc.85.7.2402)

6 Human Adiponectin ELISA Kit. User manual. B-Bridge International, Inc., UM-100101. Catalog K1001-1.

7 Soininen P, Kangas AJ, Würtz P, Tukiainen T, Tynkkynen T, Laatikainen R, Järvelin MR, Kähönen M, Lehtimäki T, Viikari J, Raitakari OT, Savolainen MJ \& Ala-Korpela M. High-throughput serum NMR metabonomics for cost-effective holistic studies on systemic metabolism. Analyst 2009134 1781-1785. (doi:10. 1039/b910205a)

8 Park JS, Cho MH, Nam JS, Yoo JS, Lee YB, Roh JM, Ahn CW, Jee SH, Cha BS, Lee EJ, Lim SK, Kim KR \& Lee HC. Adiponectin is independently associated with apolipoprotein B to A-1 ratio in Koreans. Metabolism 201059 677-682. (doi:10.1016/j.metabol. 2009.09.013)

9 Neumeier M, Sigruener A, Eggenhofer E, Weigert J, Weiss TS, Schaeffler A, Schlitt HJ, Aslanidis C, Piso P, Langmann T, Schmitz G, Schölmerich J \& Buechler C. High molecular weight adiponectin reduces apolipoprotein $\mathrm{B}$ and $\mathrm{E}$ release in human hepatocytes. Biochemical and Biophysical Research Communications 2007352 543-548. (doi:10.1016/j.bbrc.2006.11.058)

10 Qiao L, Zou C, van der Westhuyzen D \& Shao J. Adiponectin reduces plasma triglyceride by increasing VLDL catabolism. Diabetes 200857 1824-1833. (doi:10.2337/db07-0435)

11 De Vries R, Wolffenbuttel B, Sluiter W, van Tol A \& Dullaart R. Post-heparin plasma lipoprotein lipase, but not hepatic lipase activity, is related to plasma adiponectin in type 2 diabetic patients and healthy subjects. Clinical Laboratory 200551 403-409.

12 Wagner A, Simon C, Oujaa M, Platat C, Schweitzer B \& Arveiler D. Adiponectin is associated with lipid profile and insulin sensitivity in French adolescents. Diabetes and Metabolism 200834 465-471. (doi:10.1016/j.diabet.2008.02.006)

13 Ziemke F \& Mantzoros S. Adiponectin in insulin resistance: lessons from translational research. American Journal of Clinical Nutrition 201091 (Supplement) 258S-261S. (doi:10.3945/ajcn.2009.28449C)

14 Burns SF, Sojung L \& Arslanian SA. In vivo insulin sensitivity and lipoprotein particle size and concentration in black and white children. Diabetes Care 200932 2087-2093. (doi:10.2337/dc090380)

15 Tschitter O, Fritschke A, Thamer C, Haap M, Shirkavand F, Rahe S, Staiger H, Maelker E, Häring H \& Stumvoll M. Plasma adiponectin concentrations predict insulin sensitivity of both glucose and lipid metabolism. Diabetes 200352 239-243. (doi:10.2337/diabetes. 52.2.239)

16 Goropashnaya A, Herron J, Sexton M, Havel P, Stanhope K, Plaetke R, Mohatt G \& Boyer B. Relationships between plasma adiponectin and body fat distribution, insulin sensitivity, and plasma lipoproteins in Alaskan Yup'ik Eskimos: the CANHR Study. Metabolism 200958 22-29. (doi:10.1016/j.metabol.2008.09. 002)

17 Shin M \& Kim O. Plasma adiponectin is associated with less atherogenic lipoprotein phenotype. Nutrition, Metabolism, and Cardiovascular Diseases, 2011. In press. (doi:10.1016/j.numecd. 2010.01.014)

18 Mascarinec G, Steude JS, Franke AA \& Cooney RV. Inflammatory markers in a 2-year soy intervention among premenopausal women. Journal of Inflammation 20097 6-8.

Received 11 November 2010

Accepted 11 January 2011 